(6) OPEN ACCESS

\title{
Awareness and use of heated tobacco products among US adults, 2016-2017
}

\author{
Amy L Nyman, ${ }^{1}$ Scott R Weaver, ${ }^{1,2}$ Lucy Popova, ${ }^{1,3}$ Terry Frank Pechacek, ${ }^{1,4}$ \\ Jidong Huang, ${ }^{1,4}$ David L Ashley, ${ }^{1,5}$ Michael P Eriksen ${ }^{1,4}$
}

${ }^{1}$ School of Public Health,

Tobacco Center of Regulatory Science (TCORS), Georgia State University, Atlanta, Georgia, USA

${ }^{2}$ Division of Epidemiology and Biostatistics, School of Public Health, Georgia State University, Atlanta, Georgia, USA ${ }^{3}$ Division of Health Promotion and Behavior, School of Public Health, Georgia State University, Atlanta, Georgia, USA ${ }^{4}$ Division of Health Management and Policy, School of Public Health, Georgia State University, Atlanta, Georgia, USA

${ }^{5}$ Division of Environmental Health, School of Public Health, Georgia State University, Atlanta, Georgia, USA

\section{Correspondence to} Amy L Nyman, Tobacco Center of Regulatory Science (TCORS) School of Public Health, Georgia State University, Atlanta, GA 30302, USA; anyman@gsu.edu

Received 16 February 2018 Revised 27 April 2018 Accepted 30 April 2018 Published Online First 29 August 2018

\section{ABSTRACT}

Introduction Although heated tobacco products (HTP) have been on and off the commercial market for the past three decades (eg, Premier, Eclipse and Accord), they have not received widespread consumer acceptance as an alternative to combustible cigarettes. This may change with recent product innovations, shifts in consumer preferences and the tobacco market landscape and a US regulatory environment that may permit an internationally available HTP to be sold in the USA, possibly with a reduced exposure or risk statement. This study examined the extent of awareness and use of HTP in the USA and assessed the characteristics of those aware of and using these products.

Methods Data came from the 2016 and 2017 Tobacco Products and Risk Perceptions Surveys of national probability samples of US adults, conducted online during September-October $2016(n=6014)$ and AugustSeptember $2017(n=5992)$. Weighted $\chi^{2}$ tests and regression analyses examined changes in awareness and use of HTP between 2016 and 2017 and characteristics associated with awareness and use.

Results From 2016 to 2017, awareness of HTP among US adults increased from $9.3 \%$ to $12.4 \%(p<0.001)$, ever use increased from $1.4 \%$ to $2.2 \%(p=0.005)$ and current use increased two fold, from $0.5 \%$ to $1.1 \%$ $(p=0.004)$. Men and adults under age 45 years had higher rates of awareness than women and those 45 and older, respectively. Non-white adults, cigarette smokers and both current and former users of electronic nicotine delivery systems were more likely to be using HTP. Conclusions Awareness and use of HTP in the USA are increasing. These products are more familiar to men and younger adults and may be being used disproportionately by racial/ethnic minorities. With increases in HTP availability and the potential for reduced-risk claims ahead, surveillance of patterns and consequences of use by both smokers and non-smokers is needed.

\section{INTRODUCTION}

Heated tobacco products (HTP), also called 'heatnot-burn' tobacco products, contain tobacco that manufacturers claim is heated to temperatures that are below the level of combustion, ${ }^{1}$ even though recent research has called this into question. ${ }^{2}$ Users inhale a nicotine-containing aerosol created by heating the tobacco materials, instead of smoke from combustion, ${ }^{3}$ thereby reducing the intake of chemicals previously identified by Food and Drug Administration (FDA) as harmful or potentially harmful but increasing the levels of certain other constituents. ${ }^{4-7}$
HTP have been manufactured and commercially available in the USA since the 1980s but have not experienced widespread commercial success. However, the historically lacklustre consumer adoption and market failures may give way to increased appeal and consumer acceptance owing to recent product innovations, shifts in consumer preferences and the tobacco market landscape and a US regulatory environment that might soon permit an internationally available HTP to be sold in the USA, and possibly with a reduced exposure or reduced risk statement. Although many electronic nicotine delivery systems (ENDS), which typically contain no tobacco, have held promise as less-toxic substitutes for cigarettes, ${ }^{8}$ many smokers have rejected them as unsatisfying and not similar enough in feel to cigarettes. ${ }^{9} 10$ In contrast, HTP have a taste and nicotine delivery profile similar to combustible cigarettes. ${ }^{9}$ Some HTP, such as TEEPS by Philip Morris International (PMI), which uses an ignited heat source, also have an appearance and feel similar to cigarettes that may make them more appealing to smokers as substitutes for the combustible cigarette. However, some early independent research found that smokers did not perceive IQOS, another HTP from PMI that uses an electronically (battery) powered heat source, as delivering the same taste and nicotine intensity as cigarettes. ${ }^{11}$

Currently sold in markets in at least 30 countries, $^{12}$ the IQOS HTP by PMI has generated considerable consumer and market interest, as well as concerns among tobacco control proponents and policy makers. ${ }^{13}$ In South Korea, where IQOS has been available since May 2017, and in numerous other locations, PMI has sold the products in spacious, sleek stores resembling those for other high tech devices and employed sophisticated marketing strategies to engage potential users. ${ }^{14} 15$ Few studies of prevalence of the IQOS or other HTP awareness and use have been conducted. A 2017 survey of respondents ages 15 years and older in Italy, where IQOS has been available since 2014, found $19.5 \%$ of respondents were aware of IQOS and $1.4 \%$ have tried it. ${ }^{16}$ In Japan, where IQOS has been available since November 2014 and is now sold nationally along with competing HTP from Japan Tobacco and British American Tobacco (but no nicotine-containing ENDS), ${ }^{17}$ prevalence of current IQOS use increased dramatically (from $0.3 \%$ in 2015 to $3.6 \%$ in 2017) following publicity on a popular television show in April 2016. ${ }^{12} 18 \mathrm{Japa}-$ nese Google searches for HTP have also increased substantially since 2015 . $^{19}$ 
In the USA, PMI has applied to the FDA for IQOS to make claims as a Modified Risk Tobacco Product (MRTP). ${ }^{120}$ MRTPs are those tobacco products that are 'sold or distributed for use to reduce harm or the risk of tobacco-related disease associated with commercially marketed tobacco products'. ${ }^{21}$ Between May and November 2017, the FDA made the PMI MRTP application materials available online, and they were still accepting public comments on the application as of April 2018. ${ }^{20}$ Studies conducted by PMI affiliates have claimed that IQOS produces fewer harmful constituents than combustible cigarettes ${ }^{22}$ though other studies have demonstrated that these products still contain and produce toxic constituents, ${ }^{123}$ some of which may be present in even greater amounts in IQOS ${ }^{7}$ and that users are not necessarily at lower levels of risk. ${ }^{24}$ A meeting of the FDA's Tobacco Products Scientific Advisory Committee was held on 24 and 25 January 2018, during which PMI's MRTP application was debated. The ensuing discussion by the committee focused on concerns that the evidence presented by PMI was not adequate to support making modified risk or exposure claims. Unlike new tobacco product authorisation, modified risk authorisation restricts the use of modified risk claims to a limited time period, following which the applicant must demonstrate that the product and the modified risk claims continue to meet the statutory standard.

Given the popularity of HTP in Japan and elsewhere, it is expected that the commercial introduction of these products in the USA will impact consumers of nicotine and tobacco products. ${ }^{9}$ To our knowledge, there have not yet been any published studies of the prevalence of awareness and use of HTP in the USA. Early understanding of the characteristics of HTP users in the USA may indicate the trajectory these products are likely to take in the future. Of particular importance is smoker interest in HTP and whether HTP might replace ENDS as a preferred substitute (or complement) for combustible cigarettes. Also worthy of investigation are the demographic characteristics of the earliest adopters of HTP. Our data serve to provide a baseline view of HTP use and trends against which to compare subsequent use following market shifts and regulatory actions.

\section{METHODS}

\section{Study sample and procedures}

Data come from the 2016 and 2017 Tobacco Products and Risk Perceptions Surveys, annual, cross-sectional surveys of a probability sample with oversample of current cigarette smokers drawn from GfK's KnowledgePanel. Survey participants were adults ages 18 years and older and were selected with probabilities proportional to size after application of the panel demographic poststratification weight. At the sampling stage, the 2017 sample excluded anyone who completed the 2016 Tobacco Products and Risk Perceptions Survey. Data collection occurred during September and October of 2016 and during August and September of 2017. Computers with internet access were provided for those recruited panellists who did not have them. All participants received a cash equivalent of $\$ 5$ for their participation.

In 2016, 8125 KnowledgePanel members were invited to participate in the survey: 7157 members from the general population sample, of which $76.2 \%$ completed the screener and 5445 qualified for the survey and 968 members from the smoker oversample, of which $73.6 \%$ completed the screener and 616 qualified for the main survey by confirming their current smoking status. Of the 6061 qualified completers, 47 cases were excluded due to refusing to answer more than half of the survey questions, yielding an analytic sample of 6014 cases. A final stage completion rate of $74.0 \%$ was obtained for the 2016 sample.

In 2017, 8229 KnowledgePanel members were invited to participate in the 2017 survey: 7270 members from the general population sample, of which $75.1 \%$ completed the screener and 5455 qualified for the survey and 959 members from the smoker oversample, of which $68.1 \%$ completed the screener and 578 qualified for the main survey by confirming their current smoking status. Of the 6033 qualified completers, 22 cases were excluded due to refusing to answer more than half the survey questions and 19 were removed due to low duration or being flagged twice for highly improbable or incompatible responses, yielding an analytic sample of 5992 cases. A final stage completion rate of $72.8 \%$ was obtained for the 2017 sample.

A study-specific poststratification weight was computed using an iterative proportional fitting (raking) procedure to adjust for survey non-response as well as for oversampling of smokers. Demographic and geographic distributions from the most recent Current Population Survey were employed as benchmarks for adjustment, and included sex, age, race/ ethnicity, education, household income, census region and metropolitan area.

\section{Measures}

Awareness and use of HTP

In both the 2016 and 2017 surveys, all participants were shown images of Revo and IQOS HTP, chosen as examples of some types of HTP, along with the following description: 'Heat-notburn' uses leaf tobacco like traditional cigarettes. However, these products heat the tobacco to a lower temperature than traditional cigarettes to avoid burning the tobacco. When heated, they produce aerosol with nicotine, similar to electronic cigarettes. Depending on the specific product, the tobacco is heated by either a flame (with a lighter or match) or a battery. Some brands are Eclipse, Accord, Premier, Ploom, Revo and IQOS with Marlboro Heat Sticks. Participants were then asked if they had ever seen or heard of any HTP before this study. Those who reported being aware of the products were next asked if they had ever used HTP, even one or two puffs. If they answered affirmatively, they were asked if they now use it 'every day', 'some days', 'rarely' or 'not at all'. Those who reported using HTP 'every day', 'some days' or 'rarely' were classified as current users, while those who had ever used HTP, but now use it 'not at all', were classified as former users. ${ }^{25}$

\section{Cigarette smoking}

Participants who reported smoking at least 100 cigarettes in their lifetime were asked, 'Do you currently smoke cigarettes every day, some days, or not at all?'. Current smokers were those who responded 'every day' or 'some days', and former smokers were those who responded 'not at all'. Those who reported that they had not smoked at least 100 cigarettes in their lifetime were considered never smokers.

\section{ENDS use}

Participants who were aware of ENDS were asked if they had ever used ENDS, even one or two times. Ever users of ENDS were then asked if they now use them 'every day', 'some days', 'rarely' or 'not at all'. Those who responded 'not at all' were classified as 'former ENDS users' while those who responded 'every day', 'some days', or 'rarely' were classified as 'current ENDS users'. 


\section{Quit status and quit intentions}

We created a three-level quit status variable consisting of former smokers, unsuccessful quitters and those who have never tried to quit. Current smokers were asked, 'In the past, have you ever made a serious attempt to quit smoking? That is, have you stopped smoking for at least one day or longer because you were trying to quit?'. Those who answered 'yes' were classified as unsuccessful quitters, while those who answered 'no' were classified as those who have never tried to quit. Current smokers were also asked to select the statement that best describes when and if they plan to quit smoking. Responses were then grouped into four categories, 'intend to quit in the next month', 'intend to quit in the next 6 months', intend to quit sometime in the future, but not in the next 6 months' and 'never plan to quit' to form a four-level quit intentions variable.

\section{Early adopter propensity}

Participants were asked to select whether they agreed 'not at all', 'somewhat', 'a lot' or 'completely' with each of three statements: 'I usually try new products before other people do', 'When I shop, I look for what is new' and 'I like to be the first among my friends and family to try something new'. The composite measure ranged from a low score of 3 (responding 'not at all' to all three statements) to a high score of 12 responding 'completely' to all three statements).

\section{Participant sociodemographics}

Participant sociodemographics used in analyses included sex, age, education level, race/ethnicity and annual household income and were obtained from profile surveys administered by GfK to KnowledgePanel members.

\section{Statistical analysis}

Where temporal change was not being examined or patterns of associations did not differ, data from the 2016 and 2017 surveys were pooled to improve statistical precision and power. Analyses were conducted using IBM SPSS with Complex Samples module (V.25) to obtain weighted point estimates and 95\% CIs for sample sociodemographics, awareness and use of HTP, overall and by sample characteristics, quitting status and quitting intentions. Associations among awareness and use of HTP, sample characteristics, quitting status and quitting intentions were measured by weighted multivariable logistic regression models and Rao-Scott $\chi^{2}$ tests.

\section{RESULTS}

Estimates of the population sociodemographic characteristics, smoking status and ENDS use for 2016 and 2017 are shown in table 1 . In 2017, there was a significantly greater proportion of adults who currently smoked cigarettes $(p=0.003)$ and who currently used ENDS $(p<0.001)$ than in 2016. Adults in 2017 also reported greater propensity to be an early adopter of new products $(p=0.001)$ than in 2016 .

Table 2 compares awareness and use of HTP between 2016 and 2017. In 2017, $12.4 \%$ of all adults had heard of them, $2.2 \%$ had ever used them and 1.1\% reported current use of HTP. Among all adults, awareness $(\mathrm{p}<0.001)$, ever use $(\mathrm{p}=0.005)$ and current use $(p=0.004)$ increased significantly between 2016 and 2017.

Shown in table 3 are the proportions of awareness, ever use and current use of HTP by sample characteristics, as well as the adjusted ORs for sample characteristics and HTP awareness and use, for the 2016 and 2017 data combined. Adjusting for all other factors, men and those younger than age 45 years had greater odds of awareness of HTP than women and those 45 years and older, respectively. Non-white participants had greater odds of ever and current use of HTP, compared with white participants. Current cigarette smokers were nearly twice as likely to have ever used HTP as never smokers. Both former and current users of ENDS were more likely to be aware of, have ever used or be current users of HTP than those who have never used ENDS. Similarly, early adopters of new products had greater odds of awareness, ever use and current use of HTP.

Table 4 displays associations between quit status and quit intentions with awareness, ever use and current use of HTP, for the 2016 and 2017 samples. Former smokers in 2016 had lower odds of ever or current use of HTP compared with smokers who had never tried to quit. In 2017, smokers who had made quit attempts had increased odds of ever using HTP compared with smokers who had never tried to quit. Among current smokers in 2016, those who had plans to quit either in the next month or next 6 months were more than twice as likely to be aware of HTP than smokers with no plans to quit. Smokers in 2016 with plans to quit in the next 6 months also had greatly increased odds of currently using HTP compared with those with no plans to quit. There were no significant differences in awareness or use of HTP by quit intentions in 2017.

\section{DISCUSSION}

Though HTP products have not yet achieved widespread use, the number of US adults who are aware of and using these products is rapidly increasing. In 2017, ever and current use were still uncommon, $2.2 \%$ and $1.1 \%$, respectively, though the proportion for current use had more than doubled since 2016. These numbers correspond to over 7 million people in the USA ever trying and over 3.5 million currently using HTP. If patterns of usage follow those occurring in Japan, we can expect these numbers to increase substantially following commercial introduction of IQOS. Analysts predict rapid sales growth in the USA, similar to that of Japan, over the next few years. ${ }^{14}$ Caution should be used when extrapolating from the Japan example; however, as there are notable ways in which the Japanese market is different from the US market. Commercially available ENDS in Japan do not contain nicotine, ${ }^{12}$ making ENDS less competitive with other tobacco and nicotine-containing products. Government regulations are also less stringent in Japan. ${ }^{17}$

PMI's MRTP application to the FDA outlines the 'considerations (that) will ensure that the product benefits the health of the population as a whole'. ${ }^{20}$ Included are the stipulations that 'an MRTP should not increase initiation among non-users of tobacco products, and hence should not appeal to former users and never users' and 'an MRTP should not have a significant impact on the decision of a smoker who would otherwise quit smoking, ${ }^{20}$ PMI then cites studies that purport to show that IQOS is not attractive to adult never smokers and 'minimally attractive' to adult former smokers. ${ }^{20}$ While our data do show that current smokers have thus far had significantly greater odds of using HTP, there are small numbers of never and former smokers who have tried and are currently using these products. In Italy, while current cigarette smokers and current ENDS users have the highest rates of HTP (IQOS) use, a small proportion of non-smokers have tried the products as well. ${ }^{16}$ Though the number of both the Italian and US survey participants who have used HTP is small, roughly half of the Italian sample who used IQOS and just under half of the US sample who ever used any HTP are either never or former cigarette smokers. We do not know 
Table 1 Participant sociodemographics

\begin{tabular}{|c|c|c|c|c|c|}
\hline & \multicolumn{2}{|l|}{2016} & \multicolumn{2}{|l|}{2017} & \multirow[b]{2}{*}{$P$ values* } \\
\hline & Unweighted n & $\begin{array}{l}\text { Weighted \%/mean } \\
(95 \% \mathrm{Cl})\end{array}$ & Unweighted n & $\begin{array}{l}\text { Weighted \%/mean } \\
(95 \% \mathrm{Cl})\end{array}$ & \\
\hline Total & 6014 & - & 5992 & - & \\
\hline \multicolumn{6}{|l|}{ Sex } \\
\hline Male & 3013 & 48.0 (46.5 to 49.6 ) & 2987 & 48.1 (46.6 to 49.6 ) & 0.923 \\
\hline Female & 3001 & 52.0 (50.4 to 53.5 ) & 3005 & 51.9 (50.4 to 53.4$)$ & \\
\hline $30-44$ & 1213 & 24.8 (23.5 to 26.2 ) & 1183 & 24.9 (23.6 to 26.4 ) & \\
\hline $45+$ & 3820 & 54.3 (52.8 to 55.9$)$ & 3717 & $54.3(52.7$ to 55.8$)$ & \\
\hline \multicolumn{6}{|l|}{ Education } \\
\hline Less than high school & 297 & $10.8(9.6$ to 12.1$)$ & 326 & $10.8(9.7$ to 12.1$)$ & 0.961 \\
\hline High school & 1781 & 29.3 (27.9 to 30.6 ) & 1345 & 28.9 (27.5 to 30.4$)$ & \\
\hline Black, NH & 547 & $11.8(10.8$ to 12.9$)$ & 600 & $11.8(10.8$ to 12.8$)$ & \\
\hline Hispanic & 672 & 15.3 (14.1 to 16.6$)$ & 639 & 15.8 (14.6 to 17.2 ) & \\
\hline Other, NH & 361 & $7.8(6.9$ to 8.9$)$ & 388 & $8.0(7.1$ to 9.1$)$ & \\
\hline \multicolumn{6}{|l|}{ Income } \\
\hline Less than $\$ 30000$ & 1486 & 20.7 (19.6 to 22.0$)$ & 1290 & 19.1 (18.0 to 20.3 ) & 0.067 \\
\hline$\$ 30000-\$ 99900$ & 3144 & $47.4(45.9$ to 49.0$)$ & 2961 & 47.0 (45.6 to 48.5$)$ & \\
\hline$\$ 100000+$ & 1384 & 31.8 (30.3 to 33.4$)$ & 1741 & 33.9 (32.4 to 35.3$)$ & \\
\hline \multicolumn{6}{|l|}{ Cigarette smoking status } \\
\hline Never & 3107 & 59.7 (58.2 to 61.2$)$ & 3061 & 56.4 (54.9 to 57.8$)$ & 0.003 \\
\hline Former & 1619 & 27.1 (25.8 to 28.4 ) & 1660 & 28.7 (27.3 to 30.0$)$ & \\
\hline
\end{tabular}

${ }^{*} \chi^{2}$ test.

tRange from 3 to 12 .

ENDS, electronic nicotine delivery systems; $\mathrm{NH}$, non-Hispanic.

whether the former smokers who have used HTP did so before or after they stopped smoking.

PMI also claims that their test communications about the products had no significant impact on the intention of adult smokers to quit smoking. ${ }^{20}$ However, because their experimental studies did not include a control group, they cannot make causal claims on whether the messages had any impact on cessation. ${ }^{26}$
Furthermore, between $3 \%$ and $33 \%$ of participants who had intentions to quit before exposure to the messages reported lower intentions to quit after they saw the messages about IQOS with modified risk claims. ${ }^{26}$ It is possible that using messages without modified risk claims or combining the claims with stronger warnings (such as pictorial warning labels) might have prevented this decline in intentions to quit smoking.

Table 2 Awareness and use of HTP among US adults

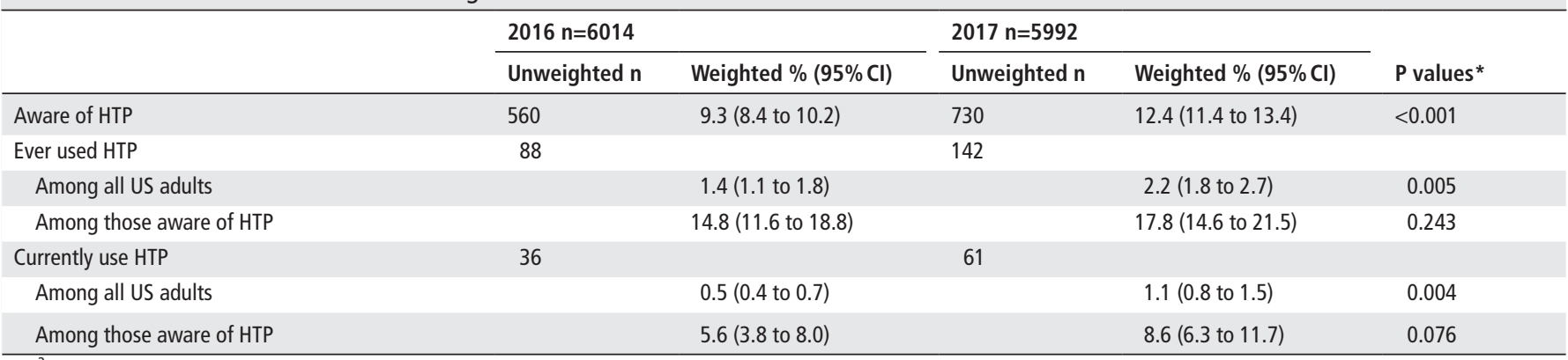


Table 3 Characteristics associated with HTP product awareness and use, among US adults, 2016 and 2017

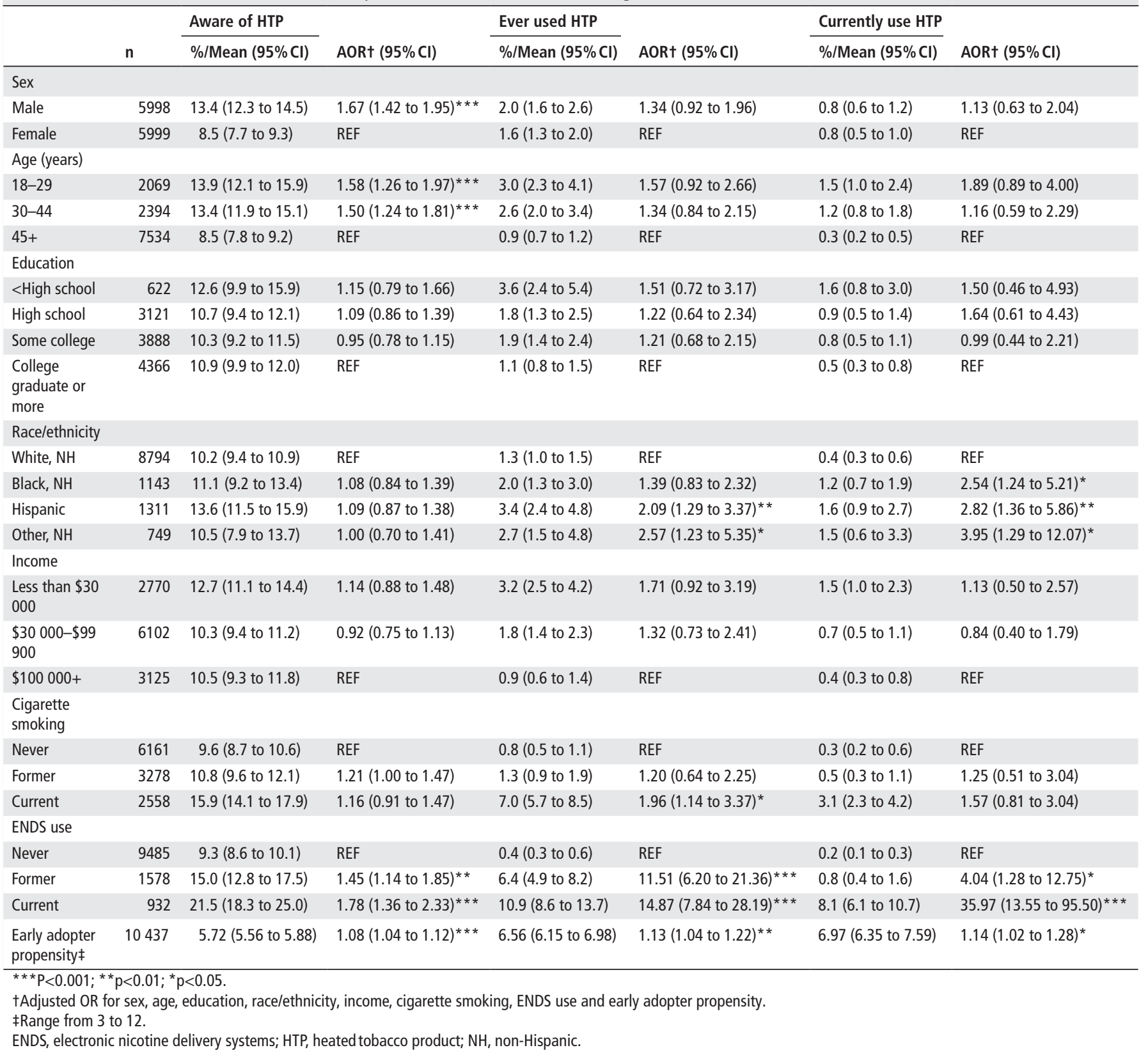

Smokers with concrete plans to quit were more likely to be aware of HTP than those with no plans to quit in 2016, but not in 2017, possibly indicating that media coverage of HTP may have contributed to expanding awareness beyond only those with intentions to quit smoking. Smokers in 2017 who had unsuccessfully tried to quit were more than twice as likely as those who have never tried to quit to have used HTP, which may indicate that HTP are increasingly being explored as quit aids among smokers who were unsuccessful with other cessation tools. We do not yet know the patterns in which HTP are being used by these groups; specifically, whether these products will be used only temporarily as smokers are trying to quit, if they will continue to be used as a substitution for quitting tobacco products entirely, or if they will be used concurrently with cigarettes, indefinitely. Careful monitoring of product uptake among non-smokers and of use among smokers trying to quit will be essential.
It is not surprising that current smokers in the USA are more likely to be aware of and using these products than those who have never smoked. More strikingly, those who have used ENDS, and current ENDS users, particularly, have much higher odds of having used HTP than never users of ENDS. It remains to be seen whether dual users of ENDS and HTP will find one product more satisfying and switch completely to that. It is also possible that smokers who have never tried (or who have tried but rejected) ENDS may consider trying HTP.

PMI's and our study did not evaluate the appeal of IQOS to youth, to whom these products should not appeal. Given the experience with ENDS in the USA, it is reasonable to assume that HTP would be appealing to youth and young adult newer smokers ${ }^{27}$ ENDS are similar to HTP in that both are alternatives to cigarettes promoted by emphasising lack of smoke and reduced harm. As rates of ENDS use have been increasing rapidly in the USA since they were first introduced 
Table 4 Awareness and use of HTP by quit status and quit intentions among current and former smokers, among US adults, 2016 and 2017

\begin{tabular}{|c|c|c|c|c|c|c|c|}
\hline & \multirow[b]{2}{*}{$\mathrm{n}$} & \multirow{2}{*}{$\begin{array}{l}\text { Aware of HTP } \\
\%(95 \% \mathrm{Cl})\end{array}$} & \multirow[b]{2}{*}{ AORt $(95 \% \mathrm{Cl})$} & \multirow{2}{*}{$\begin{array}{l}\text { Ever used HTP } \\
\%(95 \% \mathrm{Cl})\end{array}$} & \multirow[b]{2}{*}{ AORt $(95 \% \mathrm{Cl})$} & \multirow{2}{*}{$\begin{array}{l}\text { Currently use } \\
\text { HTP } \\
\%(95 \% \mathrm{Cl})\end{array}$} & \multirow[b]{2}{*}{$\mathrm{AOR}+(95 \% \mathrm{Cl})$} \\
\hline & & & & & & & \\
\hline 2016 & 6014 & & & & & & \\
\hline \multicolumn{8}{|c|}{ Among current and former smokers $(n=2904)$ : } \\
\hline \multicolumn{8}{|l|}{ Quit status } \\
\hline Former smokers & 1619 & 9.5 (8.0 to 11.3 ) & $1.06(0.63$ to 1.77$)$ & $1.0(0.6$ to 1.7$)$ & $0.24(0.10 \text { to } 0.56)^{* *}$ & $0.2(0.1$ to 0.5$)$ & $0.14(0.03 \text { to } 0.60)^{* *}$ \\
\hline Unsuccessful quitters & 895 & $13.9(11.2$ to 17.1$)$ & 1.54 (0.90 to 2.64$)$ & $5.1(3.5$ to 7.3$)$ & 0.95 (0.44 to 2.04$)$ & $2.7(1.6$ to 4.5$)$ & 1.49 (0.48 to 4.63$)$ \\
\hline Never tried to quit & 390 & 9.7 (6.3 to 14.7$)$ & REF & $5.4(2.9$ to 10.0$)$ & REF & $1.9(0.6$ to 5.5$)$ & REF \\
\hline \multicolumn{8}{|l|}{ Among current smokers $(n=1279)$ : } \\
\hline \multicolumn{8}{|l|}{ Quit intentions } \\
\hline In next month & 207 & $15.3(9.7$ to 23.3$)$ & $2.53(1.05 \text { to } 6.08)^{*}$ & 9.2 (4.6 to 17.4$)$ & 4.29 (0.87 to 21.12$)$ & 3.3 (1.2 to 8.7$)$ & 7.05 (0.91 to 54.80$)$ \\
\hline In next 6 months & 210 & 14.7 (9.4 to 22.2$)$ & $2.38(1.00 \text { to } 5.67)^{*}$ & 8.1 (4.6 to 14.1$)$ & 3.85 (0.84 to 17.67$)$ & $6.0(2.9$ to 12.0$)$ & $\begin{array}{l}15.85(2.45 \text { to } \\
102.38)^{\star *}\end{array}$ \\
\hline Future but not next 6 months & 672 & $12.6(9.7$ to 16.3$)$ & $1.97(0.95$ to 4.09$)$ & $4.0(2.3$ to 6.6$)$ & $1.62(0.40$ to 6.53$)$ & $1.6(0.7$ to 3.8$)$ & 3.49 (0.52 to 23.41$)$ \\
\hline Never plan to quit & 190 & 6.5 (3.6 to 11.5$)$ & REF & $2.3(0.7$ to 7.1$)$ & REF & $0.5(0.1$ to 2.2$)$ & REF \\
\hline 2017 & 5992 & & & & & & \\
\hline \multicolumn{8}{|c|}{ Among current and former smokers $(n=2928)$} \\
\hline \multicolumn{8}{|l|}{ Quit status } \\
\hline Former smokers & 1660 & $12.0(10.2$ to 13.9$)$ & 0.95 (0.60 to 1.51$)$ & 1.7 (1.0 to 2.6$)$ & $0.48(0.20$ to 1.15$)$ & $0.9(0.4$ to 1.9$)$ & 0.58 (0.15 to 2.22$)$ \\
\hline Unsuccessful quitters & 931 & 20.1 (16.9 to 23.8$)$ & 1.54 (0.99 to 2.41$)$ & $9.8(7.4$ to 12.7$)$ & $2.46(1.24 \text { to } 4.87)^{*}$ & 4.1 (2.6 to 6.4$)$ & 2.25 (0.81 to 6.25$)$ \\
\hline Never tried to quit & 337 & $17.0(12.4$ to 22.9$)$ & REF & 6.1 (3.4 to 10.7$)$ & REF & $2.8(1.3$ to 6.3$)$ & REF \\
\hline \multicolumn{8}{|l|}{ Among current smokers $(n=1266)$} \\
\hline \multicolumn{8}{|l|}{ Quit intentions } \\
\hline In next month & 231 & 20.3 (13.9 to 28.6$)$ & 1.02 (0.53 to 1.96$)$ & 9.9 (5.6 to 17.0$)$ & 1.72 (0.62 to 4.79$)$ & $5.2(2.1$ to 12.4$)$ & 1.51 (0.40 to 5.69$)$ \\
\hline In next 6 months & 219 & 18.5 (13.0 to 25.7$)$ & 0.94 (0.49 to 1.78$)$ & 7.8 (4.5 to 13.2$)$ & 1.45 (0.52 to 4.02$)$ & $4.2(1.9$ to 9.0$)$ & 1.25 (0.37 to 4.22$)$ \\
\hline Future but not next 6 months & 645 & 18.2 (14.6 to 22.6$)$ & 0.83 (0.48 to 1.42 ) & 8.9 (6.3 to 12.4$)$ & 1.40 (0.58 to 3.41 ) & 3.1 (1.7 to 5.6$)$ & 0.83 (0.26 to 2.62 ) \\
\hline Never plan to quit & 171 & 21.1 (14.5 to 29.7$)$ & REF & 6.5 (3.0 to 13.2$)$ & REF & 3.2 (1.3 to 7.8$)$ & REF \\
\hline
\end{tabular}

${ }^{* * *} \mathrm{P}<0.001 ;{ }^{* *} \mathrm{p}<0.01 ;{ }^{*} \mathrm{p}<0.05$.

†Adjusted OR, adjusted for sex, age, education, race and income.

HTP, heated tobacco products.

into the market, so it is likely that HTP will enjoy the same popularity.

Our data show that minority adults in the USA are significantly more likely than non-Hispanic white adults to have ever used and to be current users of HTP, even when controlling for other demographic characteristics. These findings have no precedent in the literature, as prevalence studies of these products in other countries presumably used more racially homogeneous samples. As HTP are introduced in the USA and gain popularity, it will be important to monitor this trend. The Japanese study from 2015 found that use of HTP was higher among younger people, ${ }^{18}$ and our current data appear to uphold that pattern, at least for awareness of these products. This is not surprising, as younger people are more likely to be aware of and interested in new or innovative technology, and this extends to innovative tobacco products as well. ${ }^{28} \mathrm{~A}$ separate Japanese study of education level and HTP use found no clear associations, though a larger sample size of HTP users may have produced different results. ${ }^{29}$ Usage trends among racial and ethnic minorities, younger people and those with varying levels of education could amplify tobacco-related health disparities and should be monitored as use of HTP products becomes more widespread in the USA.

\section{Limitations}

Our study is not without limitations. Our measures of HTP awareness and use featured images and descriptions of only some types and brands of HTP, and some of these products are no longer available. It is possible that some participants who were aware of or had used or were currently using HTP did not reply in the affirmative because they did not see their particular brand or recognise that the product they used fit within this definition. This measure is not specific enough to capture awareness and use of any one brand or type of HTP, but rather only of HTP generally. HTP have also been used for consuming marijuana, and though our survey description of HTP refers to use with tobacco, it is possible that some respondents reported on their use of HTP with marijuana. Our survey also did not explore where the products are being purchased (eg, online vs in stores, within the USA vs outside the USA). We did not measure risk perceptions, reasons for use, duration or intensity of use or satisfaction with HTP. Additionally, although our total sample size was large, the low prevalence of HTP use may have limited statistical power for some analyses and did not permit a finer-grain description of the sociodemographics and tobacco use characteristics of HTP users.

\section{CONCLUSIONS}

Based on current international experience, the latest generation of HTP could have a substantial impact on the US tobacco market. Significant increases in awareness and use are already apparent, with evidence that awareness is highest among men and young adults and that these products are being used in greater proportions by racial minorities. 
Cigarette smokers and ENDS users also have higher odds of both awareness and use than non-users. Continued surveillance is needed, including further exploration of the perceptions and other characteristics associated with use,and the effects of HTP use on patterns of use of other nicotine and tobacco products.

\section{What this paper adds}

- Heated tobacco products (HTP) are being marketed aggressively and gaining popularity in many countries, and Philip Morris International is seeking Food and Drug Administration authorisation to market its IQOS HTP as a modified risk product in the USA.

- Little is known about current levels of awareness and use of HTP among US adults or the characteristics of those using these products.

- Our nationally representative survey data from 2016 and 2017 show that awareness and use of HTP are low, but increasing, among US adults.

- Awareness is higher among men, younger adults, smokers and users of electronic nicotine delivery systems (ENDS), while racial and ethnic minorities, cigarette smokers and ENDS users currently have the greatest odds of using HTP in the USA. Continuing surveillance is needed, in order to monitor potential patterns and purposes associated with HTP use.

Contributors All authors conceptualised the study and approved the final version of the manuscript. ALN ran the analyses, wrote the first draft of the manuscript and revised subsequent drafts. SRW and JH provided statistical guidance, interpretation of results and contributed to writing, reviewing and revising drafts of the manuscript. LP, TFP, and DLA contributed to interpretation of results, writing, reviewing and revising drafts of the manuscript. MPE oversaw design of the parent study, reviewed manuscript drafts and provided feedback on analyses and revisions.

Funding This work was supported by the National Institute on Drug Abuse and The Food and Drug Administration (FDA) Center for Tobacco Products (CTP) (grant number P50DA036128).

Disclaimer The content is solely the responsibility of the authors and does not necessarily represent the official views of the NIH or the Food and Drug Administration.

Competing interests MPE receives unrestricted research funding support from Pfizer, Inc ('Diffusion of Tobacco Control Fundamentals to Other Large Chinese Cities' $M P E$, Principal Investigator). DLA has received funds for work done for the World Health Organization Tobacco Free Initiative and as a Special Government Employee of the US Food and Drug Administration.

\section{Patient consent Not required.}

Ethics approval Both surveys were approved by the Georgia State University Institutional Review Board, who granted a waiver of informed consent.

Provenance and peer review Not commissioned; externally peer reviewed.

Data sharing statement Per the data sharing agreement with the $\mathrm{NIH}$, the data that support the findings of this study will be made publicly available via a thirdparty data repository upon conclusion of the grant funding period. The data are also available from the principal investigator (MPE) on reasonable request.

Open access This is an open access article distributed in accordance with the Creative Commons Attribution Non Commercial (CC BY-NC 4.0) license, which permits others to distribute, remix, adapt, build upon this work non-commercially, and license their derivative works on different terms, provided the original work is properly cited and the use is non-commercial. See: http://creativecommons.org/ licenses/by-nc/4.0/

(c) Article author(s) (or their employer(s) unless otherwise stated in the text of the article) 2018. All rights reserved. No commercial use is permitted unless otherwise expressly granted.

\section{REFERENCES}

1 Auer R, Concha-Lozano N, Jacot-Sadowski I, et al. Heat-Not-Burn Tobacco Cigarettes: Smoke by Any Other Name. JAMA Intern Med 2017;177:1050-2.

2 Davis B, Williams M, Talbot P. IQOS: evidence of pyrolysis and release of a toxicant from plastic. Tob Control 2018:tobaccocontrol-2017-054104.

3 Farsalinos KE, Yannovits N, Sarri T, et al. Nicotine Delivery to the Aerosol of a HeatNot-Burn Tobacco Product: Comparison With a Tobacco Cigarette and E-Cigarettes. Nicotine Tob Res 2018:20:1004-9.

4 Bekki K, Inaba Y, Uchiyama S, et al. Comparison of chemicals in mainstream smoke in heat-not-burn tobacco and combustion cigarettes. J Uoeh 2017;39:201-7.

5 Li X, Luo Y, Jiang X, et al. Chemical analysis and simulated pyrolysis of tobacco heating system 2.2 compared to conventional cigarettes. Nicotine Tob Res 2018;51.

6 Stephens WE. Comparing the cancer potencies of emissions from vapourised nicotine products including e-cigarettes with those of tobacco smoke. Tob Control 2017:27:10-17.

7 St. Helen G, Jacob P, Nardone N, et al. IQOS: examination of Philip Morris International's claim of reduced exposure. Tob Control 2018;27(Suppl1):s30-s36.

8 Chen J, Bullen C, Dirks K. A comparative health risk assessment of electronic cigarettes and conventional cigarettes. Int J Environ Res Public Health 2017;14.

9 Caputi TL. Industry watch: heat-not-burn tobacco products are about to reach their boiling point. Tob Control 2016;26:609-10.

10 Pechacek TF, Nayak P, Gregory KR, et al. The potential that electronic nicotine delivery systems can be a disruptive technology: results from a national survey. Nicotine Tob Res 2016;18:1989-97.

11 Hair EC, Bennett M, Sheen E, et al. Examining perceptions about IQOS heated tobacco product: consumer studies in Japan and Switzerland. Tob Control 2018;27(Suppl1):s70-573.

12 Tabuchi T, Gallus S, Shinozaki T, et al. Heat-not-burn tobacco product use in Japan: its prevalence, predictors and perceived symptoms from exposure to secondhand heatnot-burn tobacco aerosol. Tob Control 2018;27:e25-e33.

13 Jenssen BP, Walley SC, McGrath-Morrow SA. Heat-not-burn tobacco products: tobacco industry claims no substitute for science. Pediatrics 2018;141.

14 Kim M. Philip Morris International introduces new heat-not-burn product, IQOS, in South Korea. Tob Control 2018;27:e76-e78.

15 Go-PopUp. Success Story: The secret behind the IQOS stores. https://www.gopopup. com/en/magazine/success-story-the-secret-behind-the-iqos-stores (accessed $27 \mathrm{Apr}$ 2018).

16 Liu X, Lugo A, Spizzichino L, et al. Heat-not-burn tobacco products: concerns from the Italian experience. Tob Control 2018:tobaccocontrol-2017-054054.

17 Bloomberg Politics. Fight for new cigarette substitute heats up Japan: QuickTake Q\&A. 2017 https://www.bloomberg.com/news/articles/2017-06-25/fight-for-new-cigarettesubstitute-heats-up-japan-quicktake-q-a (accessed 27 Apr 2018).

18 Tabuchi T, Kiyohara K, Hoshino T, et al. Awareness and use of electronic cigarettes and heat-not-burn tobacco products in Japan. Addiction 2016;111:706-13.

19 Caputi TL, Leas E, Dredze M, et al. They're heating up: Internet search query trends reveal significant public interest in heat-not-burn tobacco products. PLoS One 2017; 12:e0185735.

20 The U.S. Food and Drug Administration.. Philip Morris Products S.A. Modified Risk Tobacco Product (MRTP) Applications. 2018 https://www.fda.gov/TobaccoProducts/ Labeling/MarketingandAdvertising/ucm546281.htm (accessed 27 Apr 2018).

21 The U.S. Food and Drug Administration. Modified risk tobacco product applications - draft guidance. 2012 https://www.fda.gov/downloads/ TobaccoProducts/GuidanceComplianceRegulatoryInformation/UCM297751.pdf (accessed 27 Apr 2018)

22 Schaller JP, Keller D, Poget L, et al. Evaluation of the Tobacco Heating System 2.2. Part 2: Chemical composition, genotoxicity, cytotoxicity, and physical properties of the aerosol. Regul Toxicol Pharmacol 2016;81(Suppl 2):S27-47.

23 Protano C, Manigrasso M, Avino P, et al. Second-hand smoke exposure generated by new electronic devices (IQOS $\AA$ and e-cigs) and traditional cigarettes: submicron particle behaviour in human respiratory system. Ann Ig 2016;28:109-12.

24 Glantz SA. PMI's own in vivo clinical data on biomarkers of potential harm in Americans show that IQOS is not detectably different from conventional cigarettes. Tob Control 2018;27(Suppl1):s9-s12.

25 Weaver SR, Kim H, Glasser AM, et al. Establishing consensus on survey measures for electronic nicotine and non-nicotine delivery system use: Current challenges and considerations for researchers. Addict Behav 2018;79:203-12.

26 McKelvey K, Popova L, Kim M, et al. IQOS labeling will mislead consumers. Tob Control 2018;27(Suppl1):s48-s54.

27 McKelvey K, Popova L, Kim M, et al. Heated tobacco products likely appeal to adolescents and young adults. Tob Control 2018;27(Suppl1):s41-s47.

28 Emond JA, Soneji S, Brunette MF, et al. Flavour capsule cigarette use among US adult cigarette smokers. Tob Control 2018:tobaccocontrol-2017-054198.

29 Miyazaki Y, Tabuchi T. Educational gradients in the use of electronic cigarettes and heat-not-burn tobacco products in Japan. PLoS One 2018;13:e0191008. 